\title{
Ginástica rítmica: experiência baseada nos esportes unificados, da Special Olympics
}

\section{RESUMO}

O programa de Esporte Unificado, da Special Olympics, possibilita práticas esportivas para pessoas com e sem deficiência intelectual conjuntamente, visando à promoção da inclusão social. Fundamentado neste programa, foi realizada uma pesquisa-ação objetivando verificar possíveis implicações alcançadas por meio da implantação de um projeto de ginástica rítmica fundamentado no Esporte Unificado, sob a perspectiva dos partícipes sem deficiência. Para isso, 18 meninas, 12 com deficiência intelectual e 6 sem essa condição, realizaram aulas de ginástica rítmica, conjuntamente, por 12 semanas, com 2 sessões semanais de 2 horas cada, em uma quadra de esportes de Guaratinguetá, São Paulo, Brasil. Ao final do programa, foi empregada uma entrevista semiestruturada com as meninas sem deficiência, apreciando os dados por análise de conteúdo. Os resultados apontaram melhoras na performance das atletas, estímulo às interações entre atletas com e sem deficiência e à construção de conhecimento sobre as diversidades, alcançando atitudes de aceitação e respeito pelas diferenças.

PALAVRAS-CHAVE: Deficiência intelectual; Ginástica; Educação física e treinamento
Elisete de Andrade Leite

Mestre em Desenvolvimento Humano e Educação Universidade de Taubaté - UNITAU, Taubaté, São Paulo, Brasil

eliseteleite@hotmail.com https://orcid.org/0000-0002-5837-254X

José Luiz Rodrigues

Doutor em Educação Física

Universidade Estadual de Campinas - UNICAMP, Faculdade de Educação Física, Campinas, São Paulo,

Brasil

joseluizrodrigues2016@gmail.com (1) https://orcid.org/0000-0001-5777-6924

Maria Teresa Leitão

Doutora em Educação Física

Universidade Estadual de Campinas - UNICAMP Faculdade de Educação Física, Campinas, São Paulo, Brasil

teresa@specialolympics.org.br https://orcid.org/0000-0001-8930-5078

Keyla Ferrari Lopes

Doutora em Educação Física Universidade Estadual de Campinas - UNICAMP,

Faculdade de Educação Física

Campinas, São Paulo, Brasil keylafe@gmail.com

(1) https://orcid.org/0000-0001-9563-9218

Camila Lopes de Carvalho

Doutora em Educação Física

Universidade Estadual de Campinas - UNICAMP, Faculdade de Educação Física, Campinas, São Paulo, Brasil

camilalopes.c@hotmail.com https://orcid.org/0000-0001-8770-6062 


\title{
Rhythmic gymnastics: experience based on unified sports, Special Olympics
}

\begin{abstract}
The Special Olympics Unified Sport program enables sports practices for people with and without intellectual disabilities to work together to promote social inclusion. Based on this program, an action research was carried out aiming to verify possible implications achieved through the implementation of a rhythmic gymnastics project based on the Unified Sport, from the perspective of non-disabled participants. To that end, 18 girls, 12 with intellectual disabilities and 6 without this condition, performed rhythmic gymnastics classes together for 12 weeks, with 2 weekly sessions of 2 hours each, in a sports court in Guaratinguetá, São Paulo, Brazil. At the end of the program, a semi-structured interview with non-disabled girls was used, assessing the data by content analysis. The results showed improvements in the performance of athletes, stimulation of the interactions between athletes with and without disabilities and the construction of knowledge about the diversities, reaching attitudes of acceptance and respect for differences.
\end{abstract}

KEYWORDS: Intellectual disability; Gymnastics; Physical education and training

\section{Gimnasia rítmica: experiencia basada en los deportes unificados de las Olimpiadas Especial}

\section{RESUMEN}

El programa de deportes unificados de Olimpiadas Especiales permite prácticas deportivas para personas con y sin discapacidad intelectual conjuntamente, con vistas a la promoción de la inclusión social. Fundamentado en este programa, se realizó una investigación-acción objetivando verificar posibles implicaciones alcanzadas por medio de la implantación de un proyecto de gimnasia rítmica fundamentado en el Deporte Unificado, desde la perspectiva de los partícipes sin discapacidad. Para ello, 18 niñas, 12 con discapacidad intelectual y 6 sin esa condición, realizaron clases de gimnasia rítmica, conjuntamente, por 12 semanas, con 2 sesiones semanales de 2 horas cada una, en una cuadra de deportes de Guaratinguetá, São Paulo, Brasil. Al final del programa, se empleó una entrevista semiestructurada con las niñas sin discapacidad, apreciando los datos por análisis de contenido. Los resultados apuntaron mejoras en el desempeño de las atletas, estímulo a las interacciones entre atletas con y sin discapacidad ya la construcción de conocimiento sobre las diversidades, alcanzando actitudes de aceptación y respeto por las diferencias.

PALABRAS-CLAVE: Discapacidad intelectual; Gimnasia; Educación y entrenamiento físico 


\section{Introdução}

A modalidade de ginástica rítmica (GR) apresenta-se de forma fascinante pelas possibilidades de movimentos naturais e espontâneos envolvidos em sua prática, possibilitando a exploração da criatividade de seus praticantes. Segundo Pereira (2000), a GR é uma atividade dotada de grande versatilidade, uma vez que explora a coordenação motora, a percepção espacial e a lateralidade, assim como a consciência corporal, a postura e as qualidades físicas. Além disso, o autor afirmou que a mesma oferece inúmeras formas de exploração de movimentos físicos e estéticos, contribuindo com o desenvolvimento e/ou o aprimoramento do esquema corporal.

Desta forma, podemos considerar a significância dessa prática também para as pessoas com deficiência, como a deficiência intelectual (DI). Contudo, desenvolver essa modalidade com tal população tem sido um grande desafio devido à escassez na elaboração de métodos específicos para os atletas com essa condição, cabendo aos profissionais de educação física a elaboração de adaptações ao encontro das necessidades de cada ginasta.

Tendo em vista esse contexto, a Special Olympics elaborou um regulamento com orientações para o treinamento dessa modalidade de forma estruturada nos níveis de habilidades dos praticantes, almejando proporcionar fundamentação aos treinamentos.

Segundo Haas (2012), a Special Olympics foi criada no início de 1960, quando Eunice Kennedy Shriver organizou um acampamento de verão, em Timberlawn, para pessoas com DI, instigada pela constatação de falta de oportunidades desportivas disponíveis para crianças com essa condição. A autora ainda relatou que, naquele momento, as pessoas com deficiência vivenciavam uma fase de institucionalização, na qual eram apartadas das atividades da sociedade, sendo a Special Olympics uma oportunidade significativa de envolvê-las em atividades esportivas.

A princípio, a Special Olympics contemplou apenas atletas com DI, mas, com o decorrer dos anos, possibilitou também a participação de pessoas sem deficiência por meio da incorporação do programa denominado de Esporte Unificado. O Esporte Unificado é um programa de caráter inclusivo através do qual a prática de esportes coletivos envolve atletas com DI e atletas sem deficiência (CAREY, 2012).

Segundo a Special Olympics (2003), o Esporte Unificado, inicialmente designado de Esporte Integrado, foi introduzido pela primeira vez nos Estados Unidos durante a organização da Conferência Nacional da Special Olympics, ocorrida em Utah, no ano de 1983. Em 1989, esta modalidade foi implantada como partícipe do programa oficial da Special Olympics. Desde então, 
se tornou um meio eficaz de promover a relativização das diferenças entre as pessoas com deficiência e aquelas que não as possuem.

Em um contexto internacional, a primeira competição do Esporte Unificado aconteceu em 1991, durante os Jogos Mundiais de Verão, em Minneapolis, nas modalidades de softball, voleibol, futebol e boliche. Na data de 1996, o Comitê de Regras Esportivas da Special Olympics adotou normas específicas para cada modalidade instituída no programa.

Nesta conjuntura, a participação no Esporte Unificado tem os seguintes objetivos (SPECIAL OLYMPICS, 1992):

- Reunir atletas com e sem deficiência em um ambiente onde todos são desafiados a explorar as suas potencialidades;

- $\quad$ Fornecer a oportunidade de prática esportiva para as pessoas com deficiência intelectual;

- Conscientizar a população sobre as competências das pessoas com deficiência intelectual;

- Estimular que familiares dos atletas com deficiência também participem como atletas ou treinadores das modalidades do Esporte Unificado;

- Estimular o desenvolvimento da interação social e da afetividade entre as pessoas com e sem deficiência, por meio do estabelecimento de um espírito de equipe;

- Melhorar a autoestima de todos os atletas.

Conforme Haas (2012), a Special Olympics incide sobre a promoção da inclusão social de pessoas com deficiência intelectual. Assim, nos Esportes Unificados, os atletas com deficiência intelectual e os seus parceiros sem deficiência competem conjuntamente, contribuindo com a participação ativa das pessoas com deficiência na sociedade e com a construção de relacionamentos respeitosos uns com os outros.

Para isso, o programa de Esporte Unificado segue algumas regras fundamentadas no ideal inclusivo, como a proporcionalidade entre o número de atletas com e sem deficiência durante a realização dos jogos, sendo que cada equipe é composta em sua metade ou maioria por atletas com deficiência intelectual; a definição da função de cada atleta do time com base na habilidade do mesmo; e a permissão de que os atletas parceiros, ou seja, sem deficiência, sejam os amigos da escola, da comunidade, irmãos, primos ou os pais, não sendo permitido apenas que o técnico atue nesta função.

Segundo a Special Olympics (2012), há três modelos de composição do Esporte Unificado. No primeiro modelo, denominado "Competitivo", todos os participantes, parceiros e atletas, devem ter habilidades e táticas similares, competindo sem a necessidade de modificação das regras oficiais 
das modalidades esportivas da Special Olympics. No segundo, "Desenvolvimento", alguns dos atletas com DI possuem habilidades proporcionais aos parceiros enquanto outros apresentam maiores limitações; sem habilidades similares, os colegas com maior habilidade auxiliam os companheiros com dificuldades, estabelecendo uma equipe cooperativa. Por fim, no terceiro modelo, denominado "Recreacional", são oferecidas oportunidades para que os atletas com deficiência e os seus pares pratiquem as modalidades esportivas da Special Olympics sem seguir um treinamento ou regras rígidas, mas vivenciando essas práticas em aulas de educação física, com a comunidade ou em eventos de exposições.

Figura 1 - Modelos de composição do Esporte Unificado, da Special Olympics.

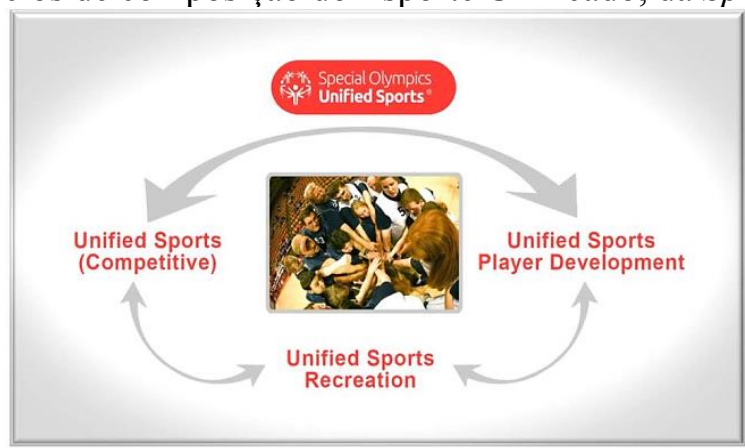

Fonte: Unified Sports Models, de Special Olympics, 2012, p.01.

Se programas como este parecem ser contributivos e benéficos à prática inclusiva, por outro lado, McConkey e Collins (2010) ressaltaram uma escassez de estudo empíricos sobre esses projetos, assim como sobre o papel de seus partícipes como promotores da inclusão social.

Nesse contexto, realizamos um estudo com atletas com e sem DI, com o objetivo de verificar possíveis implicações alcançadas por meio da implantação de um projeto de ginástica rítmica fundamentado no Esporte Unificado, sob a perspectiva dos partícipes sem deficiência.

\section{Material e métodos}

Este projeto de pesquisa foi submetido ao Comitê de Ética em Pesquisa (CEP), da Universidade de Taubaté (UNITAU) e aprovado no uso das competências definidas na Resolução CNS/MS 466/12, em junho de 2015.

O estudo foi desenvolvido e fundamentado em uma abordagem qualitativa, sendo caracterizado como pesquisa-ação, a qual é “[...] um termo que se aplica a projetos em que os práticos buscam efetuar transformações em suas próprias práticas” (BROWN; DOWLING, 2001, p. 152). 
Dessa forma, se trata de um relato de experiência de uma intervenção por meio da qual foram aproximadas ginastas com deficiência intelectual, atuantes no projeto de Ginástica Rítmica Adaptada, com ginastas de GR sem a dada condição, as quais pertenciam a um projeto de cunho particular, porém participavam de competições representando o município.

O Projeto de Ginástica Rítmica Adaptada foi implantado na cidade de Guaratinguetá, São Paulo, no ano de 2011, pela Secretaria de Educação, com o objetivo de oferecer uma atividade diferenciada e prazerosa às meninas com DI pertencentes às escolares regulares do município.

O intuito da pesquisa surgiu por meio da solicitação de uma professora de GR de atletas sem deficiência para dividir o espaço de treinamento com o grupo de ginastas com DI, suscitando a ideia de realização de um trabalho conjunto entre elas. Cônscios do programa de Esportes Unificados, da Special Olympics, iniciamos esta experiência objetivando analisar quais seriam os resultados desta intervenção.

De princípio, realizamos o convite à professora de GR das meninas sem deficiência, que concordou com o trabalho. Assim, convidamos as suas alunas para iniciarem um treinamento com as meninas com DI, direcionado a uma futura apresentação conjunta por meio do Esporte Unificado. Dentre as 18 atletas, prontamente o convite foi aceito por 6 delas, as demais alegaram não interesse em participar, o que pode ser justificado pela pouca idade das mesmas e pelo desconhecimento sobre o que seria esse novo projeto.

Por conseguinte, os componentes deste estudo foram dezoito (18) sujeitos, dos quais 12 eram meninas com DI (sendo uma com trinta anos, uma com vinte e quatro anos, duas com vinte e um anos, uma com dezesseis anos, uma com quinze anos, duas de quatorze anos, duas com doze anos, uma com dez anos e uma com oito anos) e 06 meninas sem essa condição (sendo duas com quatorze anos, duas com quinze anos e duas com dezesseis anos de idade). As atividades foram realizadas em uma quadra de esportes de uma escola pública da cidade de Guaratinguetá, em São Paulo, durante 12 semanas, com 2 sessões semanais, com duração de 2 horas cada sessão.

Para isso, foi elaborado um plano de ação flexível adequando as ações propostas ao objetivo do estudo. Um dia antes de iniciarmos a experiência, reunimos as meninas sem deficiência para uma conversa com o objetivo de relatar algumas caraterísticas principais da deficiência intelectual, objetivando superar algumas ideias pré-concebidas e explanar sobre a inexistência de um padrão físico ideal, buscando exaltar as potencialidades de cada pessoa, independente de apresentar ou não uma deficiência. 
Nos dias seguintes, foi desenvolvido o planejamento abaixo:

Quadro 1 - Plano das aulas realizadas no projeto de Esporte Unificado de Ginástica Rítmica

\begin{tabular}{|c|c|c|c|}
\hline & Conteúdo & Espaço/materiais & Objetivo \\
\hline $1^{\text {a }}$. Semana & $\begin{array}{l}\text { 1. Etapa: apresentação } \\
\text { entre as alunas e as } \\
\text { professoras. } \\
2^{\mathrm{a}} \text { Etapa: Explanação } \\
\text { sobre o objetivo do } \\
\text { projeto, assim como } \\
\text { esclarecimentos sobre a } \\
\text { adesão. Atividades } \\
\text { lúdicas na quadra. }\end{array}$ & $\begin{array}{l}\text { Quadra, } \\
\text { colchonetes e } \\
\text { aparelho de som. }\end{array}$ & $\begin{array}{l}\text { Socialização entre } \\
\text { as atletas. }\end{array}$ \\
\hline $2^{\mathrm{a}}$ Semana & 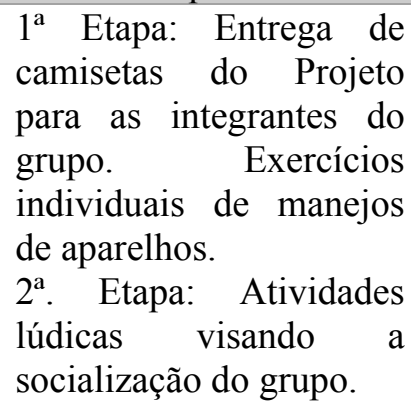 & $\begin{array}{l}\text { Quadra, } \\
\text { colchonetes } \\
\text { aparelho de som. }\end{array}$ & $\begin{array}{lr}\text { Vivencia com } & \text { os } \\
\text { aparelhos } & \text { de } \\
\text { ginástico } & \text { e } \\
\text { socialização } & \text { entre } \\
\text { as atletas. } & \end{array}$ \\
\hline $3^{a}$ semana & $\begin{array}{l}1^{\text {a }} \text {. Etapa: Atividades de } \\
\text { manejos de aparelhos em } \\
\text { duplas. } \\
2^{\mathrm{a}} \text {. Etapa: Apresentação } \\
\text { do vídeo da rotina de GR } \\
\text { a ser trabalhada em } \\
\text { conjunto. }\end{array}$ & $\begin{array}{l}\text { Quadra, } \\
\text { colchonetes, } \\
\text { aparelho de som, } \\
\text { bolas e cordas. }\end{array}$ & $\begin{array}{l}\text { Apresentação da } \\
\text { filosofia da Special } \\
\text { Olympics } \\
\text { conceituação do } \\
\text { Esporte Unificado. }\end{array}$ \\
\hline $4^{\mathrm{a}}$ semana & $\begin{array}{l}1^{\text {a }} \text { Etapa: Exercícios } \\
\text { isolados componentes de } \\
\text { uma rotina de bola em } \\
\text { grupo } \quad \text { (Special } \\
\text { Olympics). Treino dos } \\
\text { primeiros } 30 \text { segundos } \\
\text { da rotina. } \\
2^{\circ} \text { Etapa: Treino da } \\
\text { segunda parte da rotina } \\
\text { (os sequentes } 30 \\
\text { segundos). }\end{array}$ & $\begin{array}{l}\text { Quadra, } \\
\text { colchonetes, } \\
\text { aparelho de som, } \\
\text { bolas e cordas. }\end{array}$ & $\begin{array}{l}\text { Vivência } \\
\text { sequência } \\
\text { obrigatória da } 1^{\mathrm{a}} \mathrm{e} \\
2^{\mathrm{a}} \text { parte da série de } \\
\text { bola da Special } \\
\text { Olympics. }\end{array}$ \\
\hline $5^{a}$. Semana & 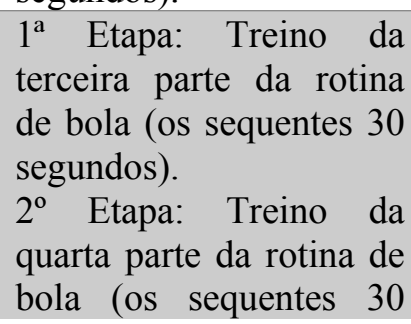 & $\begin{array}{l}\text { Quadra, } \\
\text { colchonetes, } \\
\text { aparelho de som, } \\
\text { bolas e cordas }\end{array}$ & $\begin{array}{l}\text { Vivência da } \\
\text { sequência } \\
\text { obrigatória da } 3^{\mathrm{a}} \mathrm{e} \\
4^{\mathrm{a}} \text { parte da série } \\
\text { rotina de bola da } \\
\text { Special Olympics. } \\
\text { Interação entre as }\end{array}$ \\
\hline
\end{tabular}




\begin{tabular}{|c|c|c|c|}
\hline & segundos). & & Atletas \\
\hline $6^{\mathrm{a}}$ Semana & $\begin{array}{l}1^{\text {a }} \text { Etapa: Treino } \\
\text { completo da rotina de } \\
\text { bola em grupo. } \\
2^{\text {a }} \text { Etapa: Manejo do } \\
\text { aparelho maças com o } \\
\text { grupo de nível IV. }\end{array}$ & $\begin{array}{l}\text { Quadra, } \\
\text { colchonetes, } \\
\text { aparelho de som, } \\
\text { bolas, cordas e } \\
\text { maças. }\end{array}$ & $\begin{array}{ll}\text { Interação entre } & \text { as } \\
\text { atletas e criação de } & \text { no } \\
\text { parcerias } & \text { no } \\
\text { aprendizado } & \text { do } \\
\text { manuseio } & \text { de } \\
\text { maças. } & \end{array}$ \\
\hline $7^{\mathrm{a}}$ semana & $\begin{array}{l}1^{\text {a }} \text { Etapa: Treinamento do } \\
\text { grupo de bola com a } \\
\text { rotina completa. } \\
2^{\mathrm{a}} \text { etapa: Início da } \\
\text { elaboração de uma rotina } \\
\text { com aparelho maças, } \\
\text { com orientação das } \\
\text { professoras e sugestões } \\
\text { das próprias alunas. }\end{array}$ & $\begin{array}{l}\text { Quadra, } \\
\text { colchonetes, } \\
\text { aparelho de som, } \\
\text { bolas, cordas, e } \\
\text { maças. }\end{array}$ & $\begin{array}{lr}\text { Interação entre as } \\
\text { atletas e criação de } \\
\text { parcerias r no } \\
\text { aprendizado do } \\
\text { manuseio r de } \\
\text { maças. Estímulo à } \\
\text { criatividade das } \\
\text { atletas para a } \\
\text { elaboração das } \\
\text { sequências livres. }\end{array}$ \\
\hline $8^{\mathrm{a}}$ semana & 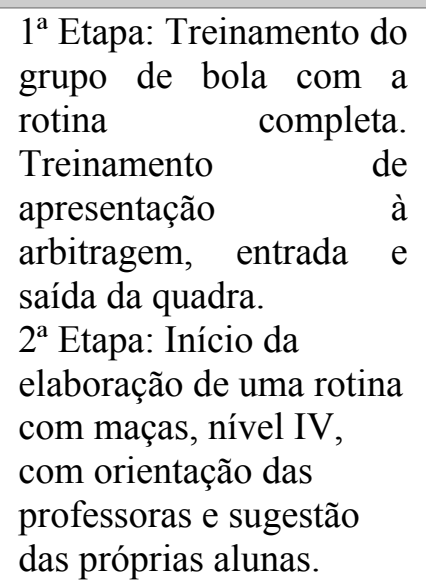 & $\begin{array}{l}\text { Quadra, } \\
\text { colchonetes, } \\
\text { aparelho de som, } \\
\text { bolas e maças. }\end{array}$ & $\begin{array}{lr}\text { Interação entre as } \\
\text { atletas e criação de } \\
\text { parcerias } & \text { no } \\
\text { aprendizado } & \text { do } \\
\text { manuseio } & \text { de } \\
\text { maças. Estímulo à } \\
\text { criatividade das } \\
\text { atletas para a } \\
\text { elaboração das } \\
\text { sequências livres. }\end{array}$ \\
\hline $9^{a}$ semana & $\begin{array}{l}1 \text { a Etapa: Treinamento do } \\
\text { grupo de bola com rotina } \\
\text { completa. Treinamento } \\
\text { de apresentação à } \\
\text { arbitragem, entrada e } \\
\text { saída da quadra. } \\
2^{\mathrm{a}} \text { etapa: Elaboração da } \\
\text { rotina com maças, nível } \\
\text { IV, com orientação das } \\
\text { professoras e sugestão } \\
\text { das próprias alunas. }\end{array}$ & $\begin{array}{l}\text { Quadra, } \\
\text { colchonetes, } \\
\text { aparelho de som, } \\
\text { bolas e maças. }\end{array}$ & $\begin{array}{l}\text { Incentivo à } \\
\text { participação em } \\
\text { grupo e parcerias } \\
\text { para a conclusão da } \\
\text { elaboração da série } \\
\text { de maças. }\end{array}$ \\
\hline $10^{\mathrm{a}}$ semana & $\begin{array}{l}1^{\text {a }} \text { Etapa: Treinamento do } \\
\text { grupo de bola com rotina } \\
\text { completa. Treinamento } \\
\text { de apresentação à } \\
\text { arbitragem, entrada e } \\
\text { saída da quadra. } \\
2^{\mathrm{a}} \text { Etapa: Elaboração da } \\
\text { rotina de maças, nível } \\
\text { IV, com orientação das } \\
\text { professoras e sugestão } \\
\text { das próprias alunas. }\end{array}$ & $\begin{array}{l}\text { Quadra, } \\
\text { colchonetes, } \\
\text { aparelho de som, } \\
\text { bolas e cordas. }\end{array}$ & $\begin{array}{l}\text { Incentivo às atletas } \\
\text { a discutirem a } \\
\text { dinâmica da } \\
\text { apresentação } \\
\text { (sequência, roupas, } \\
\text { maquiagem, } \\
\text { cabelo, e dentre } \\
\text { outros). }\end{array}$ \\
\hline
\end{tabular}




\begin{tabular}{|c|c|c|c|c|}
\hline $11^{\mathrm{a}}$ semana & 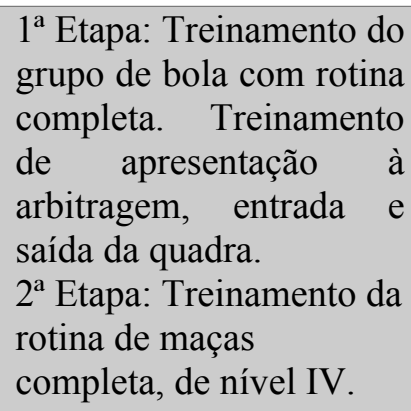 & $\begin{array}{l}\text { Quadra, } \\
\text { colchonetes, } \\
\text { aparelho de som, } \\
\text { bolas e Maças. }\end{array}$ & $\begin{array}{l}\text { Agilizar } \\
\text { organizar } \\
\text { dinâmica } \\
\text { apresentação. }\end{array}$ & $\begin{array}{r}\mathrm{e} \\
\mathrm{a} \\
\mathrm{da}\end{array}$ \\
\hline $12^{\mathrm{a}}$ semana & $\begin{array}{l}\text { Treinamentos para } \\
\text { apresentação. } \\
\text { Apresentação final da } \\
\text { experiência. }\end{array}$ & $\begin{array}{l}\text { Quadra, } \\
\text { colchonetes, } \\
\text { aparelho de som, } \\
\text { bolas e maças. }\end{array}$ & $\begin{array}{l}\text { Agilizar } \\
\text { organizar } \\
\text { dinâmica } \\
\text { apresentação. }\end{array}$ & $\begin{array}{r}\mathrm{e} \\
\mathrm{a} \\
\mathrm{da}\end{array}$ \\
\hline
\end{tabular}

A apresentação final desta experiência ocorreu em um Festival de Encerramento do Ano Letivo, realizado na própria quadra onde aconteceram os treinamentos e contando com a presença de familiares, amigos, alunos e direção da escola.

Posteriormente à intervenção, foi realizada uma entrevista semiestruturada com as atletas sem DI. A entrevista semiestruturada, segundo Manzini (1990/1991, p. 154), é uma forma de coleta de dados por meio da qual é elaborado um roteiro com perguntas referentes à temática principal a ser investigada, que podem ser complementadas por outras questões inerentes ao momento e ao contexto da entrevista.

Dessa forma, esta entrevista foi composta por questões concernentes à prática do Esporte Unificado, envolvendo itens acerca dos possíveis benefícios, da performance e do envolvimento social oriundos da participação no projeto. As entrevistas foram realizadas individualmente, com gravação de áudio em dias variados, no próprio espaço de treinamento do projeto.

Após as transcrições dos dados, estes foram apreciados por meio da análise de conteúdo, conforme Bardin (2011). Assim, foram construídas categorias de análise a partir das respostas emitidas e apontadas pelas atletas sem DI entrevistadas. As categorias foram elencadas de acordo com o objetivo da pesquisa, sendo elas "Opção por participar do projeto", "Início da participação", "Mudanças de comportamento e performance entre as atletas" e "Aceitação da família acerca da participação neste projeto".

\section{Resultados e discussão}

Por meio da realização das entrevistas com as meninas sem DI, foram obtidos os seguintes indicadores de suas respostas: 
Quadro 2 - Indicadores das respostas das meninas sem deficiência sobre a participação no projeto Esporte

\begin{tabular}{|c|c|c|c|}
\hline \multicolumn{4}{|c|}{ Unificado. } \\
\hline $\begin{array}{c}\text { Opção por participar do } \\
\text { projeto }\end{array}$ & $\begin{array}{c}\text { Início da } \\
\text { participação }\end{array}$ & $\begin{array}{c}\text { Mudanças de } \\
\text { comportamento e } \\
\text { performance entre as } \\
\text { atletas }\end{array}$ & $\begin{array}{c}\text { Aceitação da } \\
\text { família acerca } \\
\text { da } \\
\text { participação } \\
\text { neste projeto }\end{array}$ \\
\hline $\begin{array}{l}\text { Por convite da técnica; } \\
\text { para fornecer ajuda; para } \\
\text { perder a timidez e por } \\
\text { experiência nova; com } \\
\text { desconhecimento sobre os } \\
\text { Esportes Unificados. }\end{array}$ & $\begin{array}{l}\text { Sem conhecimento } \\
\text { nem contato prévio } \\
\text { com pessoas com } \\
\text { deficiência intelectual; } \\
\text { ficou com vergonha; } \\
\text { concepção de que } \\
\text { seria dificultoso } \\
\text { interagir com pessoas } \\
\text { com deficiência; não } \\
\text { sabiam como interagir } \\
\text { com as meninas com } \\
\text { essa condição de } \\
\text { deficiência. }\end{array}$ & $\begin{array}{l}\text { Mudança no modo de } \\
\text { ver e na forma de } \\
\text { pensar sobre a pessoa } \\
\text { com deficiência; } \\
\text { meninas com } \\
\text { deficiência intelectual } \\
\text { interagindo mais com } \\
\text { as demais meninas e } \\
\text { com a melhora dos } \\
\text { movimentos e da parte } \\
\text { prática da ginástica; } \\
\text { meninas sem } \\
\text { deficiência com } \\
\text { melhora na ginástica, } \\
\text { menos timidez e } \\
\text { lidando melhor com o } \\
\text { coletivo. }\end{array}$ & $\begin{array}{l}\text { Pais } \\
\text { orgulhosos, } \\
\text { achando } \\
\text { importante e } \\
\text { gostando da } \\
\text { participação no } \\
\text { grupo; } \\
\text { família sem } \\
\text { preconceitos. }\end{array}$ \\
\hline
\end{tabular}

A participação no projeto de Esporte Unificado foi aceita prontamente pelas meninas sem deficiência por convite da técnica ou por motivos pessoais, como a busca por uma experiência diferente ou para a superação de timidez, sem significativo conhecimento pelas partícipes sobre o que esperar de sua participação ou o que vivenciariam com as meninas com deficiência. Nesta inicial categoria, “Opção por participar do projeto”, constatamos que nenhuma das atletas possuía conhecimentos sobre os projetos de ginástica para pessoas com DI, nem a respeito do "Esporte Unificado". As entrevistadas relataram que passaram a conhecer essa modalidade a partir do momento em que foram convidadas a participar desse estudo.

No "Início da participação", durante a primeira semana de aulas, não foi notada expressiva interação por parte de ambos os grupos, as aulas permaneceram silenciosas, sem envolvimento entre as meninas com e sem deficiência. Apesar de estarem juntas em um mesmo local e prática, de início uma barreira atitudinal e de conhecimento impediu a interação entre as meninas, as quais foram deixadas livres nessa fase inicial, sem interferências dos professores.

Tal fato pode ser entendido quando verificado um desconhecimento da maioria das meninas sem DI acerca dessa condição de deficiência, as quais, apesar de terem recebido uma breve explanação pelos pesquisadores anteriormente à intervenção, não haviam interagido previamente com pessoas com essa condição. Assim, nesta categoria, cinco das meninas participantes 
declararam apresentar dificuldades no início das aulas por não terem contato anterior com pessoas com DI, como exemplificado nos relatos a seguir:

Entrevistada 1: No primeiro dia achei muito diferente, não conhecia meninas com deficiência e nem imaginava que elas poderiam fazer ginástica.

Entrevistada 2: No primeiro dia que tive contato com elas foi diferente porque eu nunca tinha tido esse contato com meninas com deficiência, nunca mesmo, mas eu gostei muito. Eu já tinha ouvido que elas eram agressivas, não entendiam o que você falava, que elas batiam em você, mas quando cheguei aqui vi que era diferente. Eu não tenho nenhuma pessoa deficiente em minha família pelo menos que eu saiba.

Entrevistada 3: No primeiro dia eu fiquei meio tímida porque elas têm um jeito diferente delas, elas ficam quietas no canto, elas ficam na delas aí eu fiquei meio com vergonha de conversar com elas.

Entrevistada 6: No primeiro dia eu fiquei sem jeito, não sabia como lidar com elas pelo fato delas serem especiais.

Por outro lado, com a convivência, a interação passou a ocorrer com maior frequência e intensidade, conforme explicitado na narrativa da entrevistada 5:

Entrevistada 5: Meu primeiro dia lembro que cheguei, fui apresentada ao grupo, eu tinha uma noção de como elas poderiam ser, mas eu estava errada porque elas eram diferentes do que eu imaginava, elas eram simpáticas. Eu achei que elas fossem difíceis de lidar, mas depois vi que elas eram normais, iguais a mim.

A entrevistada 6 corroborou com a afirmativa acima ao expor:

Entrevistada 6: [...] depois eu vi que era até mais fácil lidar com elas, eu me acostumei logo, porque as meninas são legais, me acolheram bem, elas são muito tranquilas em comportamentos.

A respeito desta conjuntura, Glat (1995b, p.16) explanou que nos primeiros contatos entre uma pessoa sem deficiência com uma com essa condição, sem precedentes conhecimentos ou interações, há a existência de um processo de reconstrução de um ideal pré-concebido sobre a deficiência para um no qual a convivência possibilita a construção de conhecimentos sobre a sua condição e as suas possibilidades de atuação, o que leva a uma mudança de atitude em direção a essa população:

[...] nesses indivíduos se forma uma contradição entre sua maneira de ser, e o que é considerado normal ou natural na comunidade onde vivem. Ou seja, existe uma dicotomia entre quem eles são, e - para efeitos de aceitação social - quem eles deveriam ser. 
Essa dicotomia citada pelo autor advém de um resquício histórico e social no qual as pessoas com deficiência foram submetidas a um julgamento de inferioridade em relação aos demais, sendo subordinadas a situações excludentes e depreciativas durante maior parte temporal.

A esse respeito, Januzzi (2006), Silva, Seabra Junior e Araújo (2008), assim como Carvalho (2018), narraram que, durante a maior parte do cenário histórico, as pessoas com deficiência foram vistas como incapazes, sendo exclusas do contexto social. Até o século XVII, as diferenças eram condenadas; entre os séculos XVIII, passaram a ser recusadas; já a partir da década de 1950, as diferenças sofreram uma tentativa de serem isoladas; e entre 1960 e 1970, intencionou-se uma anulação das mesmas. Apenas a partir de 1980, essas pessoas adquiriram o respaldo de uma defesa de sua aceitação, com abertura social liderada pelas famílias dessa população pela busca do respeito às diversidades e reconhecimento das potencialidades de cada pessoa para além de sua condição.

Observa-se, por conseguinte, que somente nas últimas décadas um ideal inclusivista propagou o entendimento de a diferença ser inerente a todas as pessoas, e do respeito a elas ser imprescindível, conscientizando-se que todos possuem potencialidades a ser exploradas.

Sabendo que a convivência com as diferenças contribui com a construção de conhecimentos e com a superação desses remotos entendimentos preconceituosos (LIMA; DUARTE, 2003), foi possível notar que o preconceito baseado em ideias equivocadas oriundo da ausência de contato com pessoas com DI se transformou em compreensão e aceitação das suas dificuldades por meio da participação no projeto.

Assim, na categoria "Mudanças de comportamento e performance entre as atletas", as narrativas concernentes à visualização das potencialidades das meninas com DI passaram a se destacar, como por meio do relato da entrevistada 3, ao afirmar que “[...] as meninas são esperta, são inteligentes, fazem as coisas muito belezinhas, só que elas tem um tempo diferente de aprender. Mas normal, cada um tem seu tempo" e da entrevistada 4, declarando gostar delas "[...] do jeito que elas são".

Sobre a interação entre as atletas com e sem DI, todas as entrevistas reconheceram a importância da mesma. Tal resultado encontrou similitude ao apontamento realizado no estudo de Hassall e Townsend (2007), o qual verificou que estudantes, com média de idade de 16 anos, sem deficiência, apresentaram atitudes positivas em direção aos com deficiência intelectual quando imersos na prática de Esportes Unificados.

Por conseguinte, ficou claro que as mudanças de comportamentos e performance aconteceram de forma benéfica tanto aos participantes com DI quanto aos sem a dada condição. Com a intervenção das atletas sem deficiência juntamente com a orientação dos pesquisadores, 
atuando como mediadores nas situações de ensino aprendizagem, estabeleceu-se uma credibilidade entre todas as atletas de que era possível atingir resultados positivos.

No que se refere às atletas com DI, elas ampliaram o seu aprendizado de movimentos da ginástica, superaram a timidez e desenvolveram maior interação com as outras meninas anteriormente desconhecidas, conforme notado nos relatos abaixo:

Entrevistada 1: "Eu acredito que depois dessa experiência de 12 aulas, as meninas já conseguem executar alguns movimentos com melhor qualidade. [...] Eu acho muito legal a melhora delas, elas conseguirem executar novos movimentos e a felicidade delas.

Entrevistada 2: Para elas eu acho que mudou muito, elas já imitam a gente para executar o exercício melhor.

Entrevistada 3: [...] Elas estão interagindo mais com a gente, elas não tem mais aquela vergonha de se aproximar, elas abraçam, beijam a gente, porque no começo elas ficavam distantes.

Entrevistada 5: As atletas especiais evoluíram muito na parte prática da ginástica, elas demoram mais para aprender, mas elas aprendem, nós as ajudamos e as incentivamos e isso contribui muito com elas.

Entrevistada 6: As atletas com DI evoluíram muito com a gente, porque elas prestam atenção nas nossas explicações, elas aceitam e acabam superando as dificuldades.

Por sua vez, para as meninas sem deficiência, durante as intervenções foi exposta a importância de que o contato delas com as meninas com DI fosse fundamentado no respeito, buscando identificar as potencialidades das meninas com a dada condição. As atitudes de protecionismo deveriam ser descartadas, lembrando sempre que apesar de qualquer dificuldade, as pessoas com deficiência também precisam adquirir autonomia e independência para uma atuação mais ativa e participativa na sociedade. Com isso, a inclusão propiciada pelo programa do Esporte Unificado permitiu que elas conhecessem e aprendessem a lidar com as diferenças, podendo contribuir com a formação de cidadãs mais humanas e respeitadoras, e incidindo sobre as suas futuras atuações nos variados contextos sociais, conforme exposto a seguir:

Entrevistada 2: Na minha vida mudou muito minha postura, antes de eu entrar eu não tinha consciência do que era a pessoa com deficiência.

Entrevistada 4: É gratificante porque a gente aprende pensar mais no próximo, e se tornar uma pessoa melhor. Eu gosto muito delas e elas gostam de mim. Eu gosto delas do jeito que elas são.

Entrevistada 5: Do primeiro dia até os dias de hoje eu mudei muito, sei lidar melhor com o coletivo, com as meninas, eu vi mudança na minha parte e na parte das minhas amigas que não são DI que estão no time.

Entrevistada 6: Eu mudei na minha forma de pensar, todas nós somos iguais o que muda são os nossos desafios. 
Os benefícios alcançados por ambos os grupos de participantes podem ser compreendidos quando retomado a afirmação de Vygotsky (2007) acerca do desenvolvimento do indivíduo ocorrer por meio da interação social, ou seja, de sua interação com outros indivíduos e com o meio. Assim, o autor defendeu que o cérebro humano é um sistema aberto, de grande plasticidade, cuja estrutura e modo de funcionamento são moldados ao longo da história da espécie e do desenvolvimento individual, apontando-nos que o homem transforma-se de biológico em sócio histórico, criando assim processos adaptativos para que possa superar alguns impedimentos que o impossibilitem de algumas ações, tais como se mostraram presentes nesse estudo.

Quanto à "Aceitação da família acerca da participação neste projeto", nos chamou a atenção não haver preconceito evidente das famílias em relação às meninas com deficiência, fato que nos indica um avanço na sociedade em se tratando de inclusão social.

\footnotetext{
Entrevistada 1: Meus pais estão muito orgulhosos de eu estar participando. Entrevistada 2: Meus pais quando souberam que eu ia participar do grupo acharam muito importante, gostaram muito.

Entrevistada 4: Minha família acha muito legal eu participar desse grupo. Eu não tenho preconceito nenhum, e nem minha família.
}

Glat (1995a) apontou que a rejeição da sociedade em relação às pessoas com deficiência intelectual reflete a própria fragilidade social, considerando que tudo o que foge ao padrão de normalidade pode provocar reações diversas. Desta forma, seria então a discriminação e o preconceito barreiras a serem enfrentadas pelas famílias no processo de inclusão. Nesse contexto, McConkey et al. (2013), ao pesquisarem sobre a promoção social da inclusão, constataram que, de fato, o esporte unificado resulta em maior inclusão social dos atletas.

Se essas barreiras já estão sendo transpostas, torna-se mais fácil contar com pessoas que apoiem medidas para garantir que as pessoas com deficiência não sejam segregadas e excluídas da sociedade.

Segundo Haas (2012), a força do Esporte Unificado reside na sua capacidade de construir inclusão e capital social. A inclusão social refere-se ao sentimento de pertença de um indivíduo dentro de sua comunidade e isso está intimamente interligado com o conceito de capital social, que se refere às redes, normas e relações de confiança que ligam um indivíduo a uma comunidade. $\mathrm{O}$ esporte unificado constrói capital social e inclusão social empoderando as pessoas com deficiência intelectual a estarem presentes na comunidade com participações significativas, construindo relacionamentos e amizades com os outros e rompendo barreiras que impedem a inclusão.

Shriver (1997), Siperstein (2001), Siperstein e Hardman (2001) e a Special Olympic (2003), em estudos desenvolvidos visando analisar a operação e a influência do programa de Esporte 
Unificado, confirmaram que o mesmo tem um impacto positivo em todos os envolvidos, proporcionando uma evolução nas habilidades esportivas dos participantes. Além disso, evidenciaram que os atletas sentiram prazer em participar do programa e os técnicos mostraram-se preparados para prover a assistência necessária que um time unificado demanda. Os erros e equívocos durante os treinamentos foram semelhantes àqueles que ocorrem dentro de um time convencional. Do ponto de vista dos pais dos atletas, esses estudos apontaram que o programa ampliou o acesso à informação, auxiliando-os no melhor entendimento acerca das deficiências e de como interagir com elas.

De forma corroborativa a esses apontamentos, McConkey et al. (2013, p.06), em pesquisa sobre a promoção social da inclusão, afirmou que, por meio do Esporte Unificado:

- Ambos os atletas e os parceiros relatam várias melhorias em suas habilidades no campo esportivo, em relação à resistência melhorada e habilidades técnicas as quais foram endossadas por treinadores e pais;

- Todos os informantes comentaram sobre a melhoria das habilidades interpessoais dos jogadores. Estas incluem um crescimento da autoconfiança, autoestima e do desenvolvimento de confiança, como também melhora nas habilidades comunicativas;

- $\quad$ Esportes Unificados oferecem oportunidades para os jovens desenvolverem as habilidades necessárias para se tornar mais socialmente incluídos, primeiro dentro de equipes, mas depois com os outros.

Haja vista essas significativas contribuições em direção à construção de conhecimentos sobre as diversidades e de aquisição de respeito e de valorização das diferenças, que são imprescindíveis para a efetivação de uma sociedade de fato inclusiva, a relevância da realização deste estudo se destacou, assim como a necessidade de que contínuas futuras pesquisas sejam desenvolvidas visando construir e propagar informações orientando sobre as possibilidades e metodologias de implantação de práticas para pessoas com DI em um contexto inclusivo, como no Esporte Unificado.

\section{Conclusões}

Atualmente, ainda nos deparamos com uma organização e estrutura social que, em muitos momentos, mantém um pensamento de estigmatização da deficiência, com ocorrências de preconceitos e dificuldades das pessoas com deficiência em usufruir de seus direitos enquanto cidadãos. Por falta de conhecimentos, muitas pessoas ainda enxergam as pessoas com deficiência com inferioridade, desconsiderando as suas potencialidades para as diversas atividades do cotidiano. 
Nesta circunstância, o esporte tem sido uma ferramenta significativa no processo de efetivação do ideal inclusivo na sociedade. Através de práticas esportivas, as pessoas exploram habilidades fundamentais para o seu desenvolvimento global, propiciando benefícios físiológicos e psicológicos, ao mesmo tempo no qual contribui com a propagação de valores como coletivismo, afetividade e solidariedade.

Ao introduzirmos o modelo do Esporte Unificado por meio de um projeto de GR, foi notória tanto a melhora na aprendizagem das práticas dos fundamentos da ginástica, quanto o desenvolvimento de competências sociais fundamentadas por uma interação positiva entre as atletas com e sem deficiência intelectual.

Pressupõe-se que a satisfação e a alegria manifestada pelo grupo de estar entre parceiras nessa interatividade puderam conduzir a uma aprendizagem espontânea e eficaz. Outro ponto significante de todas as entrevistadas é o relato de não haver nenhum preconceito por parte das famílias pelo fato de elas estarem envolvidas com as pessoas com deficiência.

Constatamos, assim, que essa interação promoveu atitudes positivas de encorajamento no enfrentamento dos desafios da inclusão na busca da aceitação social entre as atletas envolvidas, contribuindo com a construção de uma cultura de inclusão social das atletas com deficiência.

\section{REFERÊNCIAS}

BARDIN, Laurence. Análise de conteúdo. São Paulo: Edições 70, 2011.

BROWN, Andrew; DOWLING, Paul. Doing research/reading research: a mode of interrogation for teaching. Londres: Routledge Falmer, 2001.

CAREY, Molly. Unified Sports: providing opportunities for students with disabilities. 2012. Recuperado de: https://media.specialolympics.org/.../sports.../unified-sports/McCar.

CARVALHO, Camila Lopes de. Reflexões sobre a inclusão na educação física escolar: a tríade legislação, conhecimento acadêmico e prática profissional. 2018. Tese (Doutorado em Educação Física) - Faculdade de Educação Física, Universidade Estadual De Campinas, Campinas, 2018.

LIMA, Sônia Toyoshima; DUARTE, Edison. Atividade física para pessoas com necessidades especiais. Rio de Janeiro: Guanabara Koogan, 2003.

GLAT, Rosana. A integração social dos portadores de deficiência: Uma reflexão. Rio de Janeiro: Viveiros de Castro, 1995a.

GLAT, Rosana. Somos iguais a vocês: Depoimentos de mulheres com Deficiência Intelectual. Rio de Janeiro: Agir, 1995b. 
HAAS, Kasey. Special Olympics: An Emerging Player in the Sport for Development Field. Brown University: Special Olympics Inc., 2012. Recuperado de: https://www.specialolympics.org/

HASSALL, John; TOWNSEND, Michael. Mainstream students' attitudes to possible inclusion in Unified Sports with students who have an intellectual disability. Journal of Applied Research in Intellectual Disabilities, v. 20, n. 3, p. 265-273, 2007. https://doi.org/10.1111/j.1468-

$\underline{3148.2006 .00329 . x}$

JANNUZZI, Gilberta. A educação do deficiente no Brasil: dos primórdios ao início do século XXI. 2. ed. Campinas: Autores Associados, 2006.

MANZINI, Eduardo. A entrevista na pesquisa social. Didática, v. 26/27, n. 1, 149-158, 1990/1991.

MCCONKEY, R.; COLLINS, S. O papel do apoio pessoal na promoção da inclusão social de pessoas com dificuldades intelectuais. Jornal da Deficiência Intelectual Pesquisa, v. 54, n. (01), p. $691-700,2010$.

MCCONKEY, Roy; et al. Promoting social inclusion through Unified Sports for youth with intellectual disabilities: a five-nation study. Journal of Intellectual Disability Research, v. 57, n. 10, p. 923-935, jun. 2013. DOI:10.1111/j.1365-2788.2012.01587.x

PEREIRA, Sissi Martins. Ginástica Rítmica: uma abordagem escolar. Rio de Janeiro: Shape, 2000.

SHRIVER, Timothy. Effects of the Special Olympics World Games on attitudes of nonhandicapped children toward persons with mental retardation. 1997. Tese (Doutorado) University of Connecticut, Connecticut, 1997.

SILVA, Rita de Fátima; SEABRA JUNIOR, Luiz; ARAÚJO, Paulo Ferreira. Educação Física Adaptada no Brasil: da história à inclusão educacional. São Paulo: Phorte, 2008.

SIPERSTEIN, Gary. National Evaluation of the Special Olympics Unified Sports Program. 2001. Disponível :

https://media.specialolympics.org/.../sports/unified sports report.... Acesso em: 03 mai. 2019.

SPECIAL OLYMPICS. Unified Sports Guidebook. Washington, D.C.: Special Olympics, 1992.

SPECIAL OLYMPICS. Unified Sports Handbook, 2003. Disponível em:

https://media.specialolympics.org/soi/files/sports/UnifiedSports.pdf Acesso em: 03 mai. 2019.

SPECIAL OLYMPICS. Unified Sports Models, 2012. Disponível em:

https://media.specialolympics.org/.../Unified-Sports-Models.pdf Acesso em: 03 mai. 2019.

VYGOTSKY, Lev. A formação social da mente. 7. ed. São Paulo: Martins Fontes, 2007. 


\section{NOTAS DE AUTOR}

\section{AGRADECIMENTOS}

Não se aplica.

\section{CONTRIBUIÇÃO DE AUTORIA}

Não se aplica.

\section{FINANCIAMENTO}

Não se aplica.

\section{CONSENTIMENTO DE USO DE IMAGEM}

Não se aplica.

\section{APROVAÇÃO DE COMITÊ DE ÉTICA EM PESQUISA}

A pesquisa foi submetida ao Comitê de Ética em Pesquisa da Universidade de Taubaté e aprovada com o número de parecer 1.117.130, na data de 22 de junho de 2015. O parecer em questão se encontra submetido como documento suplementar na página da Revista Motrivivência, e também em anexo ao final desse documento.

\section{CONFLITO DE INTERESSES}

Não houve conflitos de interesse na elaboração deste manuscrito.

\section{LICENÇA DE USO}

Os autores cedem à Motrivivência - ISSN 2175-8042 os direitos exclusivos de primeira publicação, com o trabalho simultaneamente licenciado sob a Licença Creative Commons Attribution Non-Comercial ShareAlike (CC BY-NC SA) 4.0 International. Esta licença permite que terceiros remixem, adaptem e criem a partir do trabalho publicado, desde que para fins não comerciais, atribuindo o devido crédito de autoria e publicação inicial neste periódico desde que adotem a mesma licença, compartilhar igual. Os autores têm autorização para assumir contratos adicionais separadamente, para distribuição não exclusiva da versão do trabalho publicada neste periódico (ex.: publicar em repositório institucional, em site pessoal, publicar uma tradução, ou como capítulo de livro), com reconhecimento de autoria e publicação inicial neste periódico, desde que para fins não comerciais e compartilhar com a mesma licença.

\section{PUBLISHER}

Universidade Federal de Santa Catarina. Programa de Pós-Graduação em Educação Física. LaboMídia - Laboratório e Observatório da Mídia Esportiva. Publicado no Portal de Periódicos UFSC. As ideias expressadas neste artigo são de responsabilidade de seus autores, não representando, necessariamente, a opinião dos editores ou da universidade.

\section{EDITORES}

Mauricio Roberto da Silva, Giovani De Lorenzi Pires, Rogério Santos Pereira.

\section{HISTÓRICO}

Recebido em: 03 de Maio de 2019.

Aprovado em: 08 de Julho de 2019. 